\title{
A genomic approach reinforces a hypothesis of mitochondrial capture in eastern Australian rosellas
}

\author{
Ashlee Shipham, ${ }^{1 *}$ Daniel J. Schmidt, ${ }^{1}$ Leo Joseph, ${ }^{2}$ and Jane M. Hughes ${ }^{1}$ \\ ${ }^{1}$ Griffith University, Australian Rivers Institute, Griffith School of Environment, Nathan, Queensland, Australia \\ 2 Australian National Wildlife Collection, CSIRO National Research Collections Australia, Canberra, Australian Capital Territory, \\ Australia \\ * Corresponding author: ashlee.shipham@griffithuni.edu.au \\ Submitted February 6, 2016; Accepted September 11, 2016; Published December 7, 2016
}

\begin{abstract}
Recently, there have been contradictory results regarding relationships among 3 Australian parrot species known commonly as the Northern (Platycercus venustus), Pale-headed ( $P$. adscitus), and Eastern rosella ( $P$. eximius). An early phylogenetic analysis of the rosella genus Platycercus found that $P$. adscitus and $P$. eximius, 2 species putatively forming a hybrid zone, were sister taxa, while the geographically isolated $P$. venustus was in turn their sister taxon. However, a recent reexamination using multilocus sequence data found that evolutionary relationships differed depending on marker choice. Mitochondrial DNA (mtDNA) supported the earlier finding, but nuclear sequence data reflected an alternative relationship aligning $P$. adscitus and $P$. venustus as sister taxa. Two hypotheses were proposed to reconcile the discordance: (1) incomplete lineage sorting, and (2) mtDNA introgression from $P$. adscitus into populations of $P$. eximius. To clarify the relationships among these 3 species and to distinguish between the proposed hypotheses, restriction site-associated DNA (RAD) sequencing data from 23 individuals ( 4 individuals per subspecies) were examined. Species trees were generated based on datasets either excluding loci with missing data (393 loci) or including them (5 nonoverlapping subsets of 1,000 loci). Findings strongly supported a sister relationship between $P$. adscitus and $P$. venustus (posterior probabilities of 1 at all nodes), suggesting that the discordant patterns previously identified may have been the result of mitochondrial introgression and/or capture. This and other potential explanations are discussed.
\end{abstract}

Keywords: Platycercus, introgression, mitonuclear discordance, phylogenetics, restriction site-associated DNA (RAD) sequencing, Eastern Rosella, Pale-headed Rosella, Northern Rosella

\section{Une approche génomique renforce une hypothèse de capture mitochondriale chez des perruches de l'est de I'Australie}

\section{RÉSUMÉ}

Des résultats contradictoires ont récemment été publiés concernant les relations entre trois espèces de perruches australiennes, soit Platycercus venustus, $P$. adscitus et $P$. eximius. Une analyse phylogénétique préliminaire du genre Platycercus a révélé que $P$. adscitus et $P$. eximius, deux espèces formant une zone hybride putative, étaient des taxons sœurs, tandis que l'espèce isolée géographiquement $P$. venustus était également leur sœur. Toutefois, un récent réexamen des données des séquences multilocus a révélé que les relations évolutives différaient selon le choix du marqueur. L'ADN mitochondriale (ADNmt) a appuyé les résultats antérieurs, mais les données des séquences nucléaires reflétaient une relation alternative alignant $P$. adscitus et $P$. venustus comme des sœurs. Deux hypothèses ont été proposées afin de concilier les éléments de discordance : (1) un triage incomplet des lignées et (2) une introgression de l'ADNmt de $P$. adscitus dans les populations de $P$. eximius. Afin de clarifier les relations entre ces trois espèces et de distinguer les hypothèses proposées, des données de séquençage de l'ADN associé à un site de restriction (RAD) provenant d'un total de 23 individus ( $\sim 4$ individus par sous-espèce) ont été examinées. Les arbres des espèces étaient générés à partir d'ensembles de données excluant les loci avec des données manquantes (393 loci) ou les incluant (cinq sous-ensembles de 1000 loci qui ne se chevauchent pas). Les résultats appuient fortement I'hypothèse d'une relation sœur entre $P$. adscitus et $P$. venustus (probabilités postérieures de 1 à tous les nœuds), suggérant que les patrons discordants préalablement identifiés peuvent être le résultat d'une introgression et/ou d'une capture mitochondriale. Ceci et d'autres explications possibles sont discutées.

Mots-clés: Platycercus, introgression, discordance mito-nucléaire, phylogénétique, séquençage de l'ADN associées à un site de restriction (RAD), Platycercus eximius, Platycercus adscitus, Platycercus venustus 


\section{INTRODUCTION}

The rosella genus (Platycercus) encompasses a group of medium-sized ( $\sim 25-37 \mathrm{~cm}, 55-125$ g; Forshaw 2002) Australian platycercine parrots (Cain 1955, Higgins 1999). Previous phylogenetic assessments of the group have been inconsistent in their findings, particularly with respect to 3 of the 4 species placed in the subgenus Violania: $P$. venustus (Northern Rosella), P. adscitus (Pale-headed Rosella) and $P$. eximius (Eastern Rosella). We note that the $4^{\text {th }}$ member of the subgenus Violania (P. icterotis; Western Rosella) is sister to the other 3 and will be considered no further here. While $P$. venustus is geographically isolated from the other 2 species (Forshaw 2002), there is an assumed hybrid zone between $P$. adscitus and the 2 currently recognized subspecies of $P$. eximius that are found on continental Australia ( $P . e$ eximius and $P$. e. elecica). To date, assessments of this hybrid zone have been based on morphological characteristics, which show intermediacy between the 2 species (Cannon 1984, Schodde 1997). An early phylogenetic analysis of the rosella genus (Ovenden et al. 1987) used restriction fragment length polymorphisms (RFLPs) in mitochondrial DNA (mtDNA), and concluded that $P$ adscitus and $P$. eximius were the most closely related taxa among the 3 species. However, a recent multilocus analysis of the genus incorporating both mitochondrial (ND2) and nuclear (9 loci) DNA sequence data found that relationships varied depending on marker choice. The single mitochondrial locus found $P$. adscitus and nominotypical subspecies $P$. e. eximius to be sister taxa, which supported the original finding, but analyses incorporating nuclear data found $P$. adscitus to be more closely related to $P$. venustus than $P$. eximius (Shipham et al. 2015). Additionally, when all data were included in analyses, the $3^{\text {rd }}$ currently recognized subspecies of $P$. eximius ( $P$. e. diemenensis), which is confined to the island of Tasmania, aligned with $P . e$. eximius. However, when examining mitochondrial DNA in isolation (Shipham et al. 2015), individuals of $P$. $e$. diemenensis were sufficiently divergent for this subspecies to be considered a sister taxon to the rest of the rosellas in the subgenus Violania. Instances of mitonuclear discordance are becoming increasingly prevalent in the literature, and a number of potential explanations have been proposed, such as adaptive introgression, demographic differences between groups of interest, or sex-biased asymmetries in mate selection or offspring survival (see Toews and Brelsford 2012).

For rosellas in the subgenus Violania, 2 hypotheses have been proposed to explain the discrepancy between purely mitochondrial datasets and those incorporating nuclear data (Shipham et al. 2015). Firstly, the relationships identified when analyzing nuclear data may be the result of incomplete lineage sorting (ILS), a phenomenon by which ancestral polymorphisms are retained after speciation events (Degnan and Rosenberg 2009, Steiner et al. 2012, Corl and Ellegren 2013). This has the potential to impede accurate phylogenetic inference and is a common problem when examining nuclear data (McLean et al. 2012, Leache et al. 2014), particularly for taxa that have arisen relatively recently (Degnan and Rosenberg 2009, Steiner et al. 2012, Corl and Ellegren 2013). This hypothesis was supported for Violania by the low posterior probabilities and topological inconsistencies that arose when only nuclear loci were included in a species tree (Shipham et al. 2015). Alternatively, hybridization between the 2 parapatrically distributed species may have facilitated mitochondrial introgression or capture, potentially from $P$. adscitus into the 2 currently recognized subspecies of $P$. eximius that are found on mainland Australia, the isolated Tasmanian subspecies still showing the 'true' mtDNA of $P$. eximius. Given that support for species tree topologies found by Shipham et al. (2015) was not consistently high, even when all loci were included in analyses (i.e. posterior probabilities for key nodes were as low as 0.61), further study is warranted.

Here, we reexamine the evolutionary relationships among the 3 taxa using an approach that offers greater power for accurate phylogenetic reconstruction than that presented by Shipham et al. (2015). Restriction siteassociated DNA (RAD) sequencing is an approach that permits genome-wide sampling of thousands of loci (Baird et al. 2008). It requires no prior genomic resources and identifies single nucleotide polymorphisms (SNPs) in close proximity to restriction enzyme cut sites (McCormack et al. 2013, Toews et al. 2016). The method has been increasingly applied to phylogenetic assessment, where it has shown great promise for resolving phylogenetic and phylogeographic problems, as well as species delimitation questions, in a range of taxonomic groups (Emerson et al. 2010, DaCosta and Sorenson 2016, Herrera and Shank 2016). The method is best suited to groups that have diverged relatively recently (McCormack et al. 2013, DaCosta and Sorenson 2016, Toews et al. 2016), as the number of orthologous restriction sites decreases with increasing divergence (Herrera and Shank 2016, Toews et al. 2016). For these reasons, it is an appropriate method for analysis of evolutionary relationships among rosellas in the subgenus Violania, which have been proposed to have diverged since the Pleistocene, and potentially as recently as 0.1617 mya (but see Shipham et al. [2015] for assumptions and limitations associated with this date).

This study used RAD sequencing to clarify the evolutionary relationships among the $P$. venustus $-P$. adscitus-P. eximius group. We aimed to distinguish between the hypothesis of mitochondrial introgression from $P$. adscitus into $P$. eximius and that of ILS as discussed by Shipham et al. (2015). A sister relationship between $P$. 


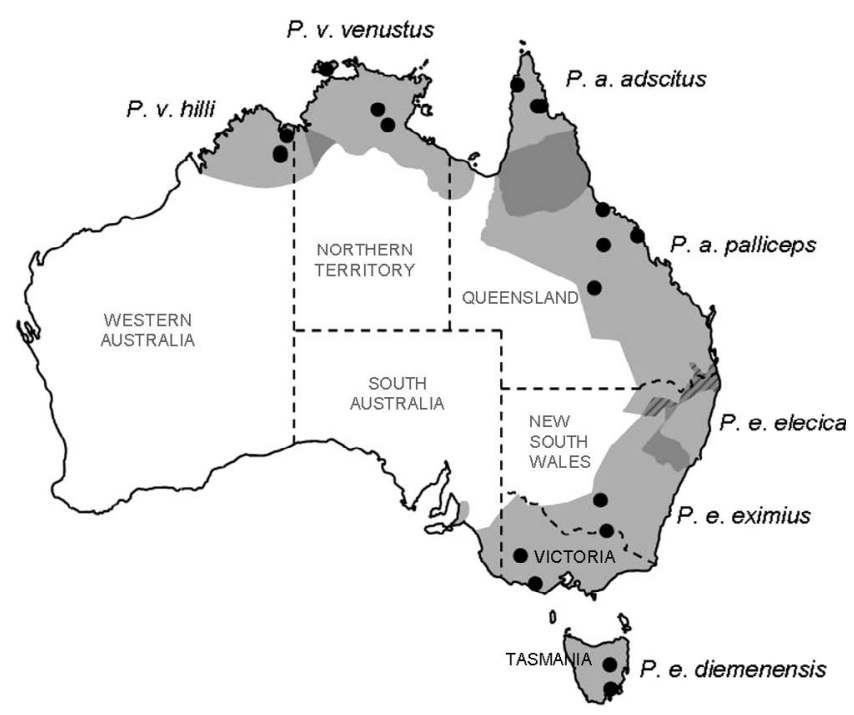

FIGURE 1. Sampling localities for individuals used in restriction site-associated DNA (RAD) sequencing analyses (black dots) and approximate species ranges (shaded regions) of Platycercus venustus, $P$. adscitus, and $P$. eximius. Areas shaded in dark gray with diagonal stripes represent overlapping ranges between $P$. adscitus and $P$. eximius. Areas shaded in dark gray without stripes represent reported overlapping ranges between subspecies within a species. Species boundaries pictured here were approximated based on descriptions by Schodde (1997). Note that some circles represent multiple individuals. For locations relating to each individual, see Appendix Table 3.

adscitus and $P$. eximius may suggest that ILS produced the nuclear pattern identified by Shipham et al. (2015). Alternatively, a sister relationship between $P$. adscitus and $P$. venustus would lend confidence to the alternative view that mitonuclear discordance in patterns of relationships among the 3 taxa reflects introgression of mtDNA. When coupled with the mitochondrial data presented by Shipham et al. (2015), the most likely explanation for this would be mitochondrial introgression from or capture by $P$. adscitus into mainland populations of $P$. eximius. We also discuss the plausibility of other possible explanations that were not discussed by Shipham et al. (2015).

\section{METHODS}

\section{Taxon Sampling}

Tissue samples were provided by the Australian National Wildlife Collection (ANWC; Canberra, Australian Capital Territory, Australia). Total sample size for RAD sequencing analyses was 23 individuals (P. a. adscitus: $n=4 ; P$. $a$. palliceps: $n=4$; P. e. eximius: $n=4$; P. e. diemenensis: $n=4$; $P$. v. venustus: $n=4 ; P$. v. hilli: $n=3$ ). When possible, for comparability, individuals used in Shipham et al.s (2015) phylogenetic analysis were included here. When this was not possible, individuals that occupied a similar geographic location were substituted. The overall sampling design was one that incorporated individuals from across the regions where species or subspecies were allopatrically distributed in an effort to capture variation within each group, and was also aimed at minimizing the negative impact of putative contemporary hybridization and introgression between $P$. adscitus and P. eximius (Figure 1, Appendix Table 3). For this reason, $P$. e. elecica was excluded, given its close proximity to the putative hybrid zone and proposed intergradation with both $P$. a. palliceps and $P$. e. eximius (Figure 1; Schodde 1997). A total of 23 ND2 sequences were also taken from Shipham et al. (2015) for comparison with RAD sequencing results $(4 \times P$. e. eximius, $3 \times P . e$. diemenensis, $3 \times P$. venustus, $4 \times P$. adscitus, $2 \times P$. icterotis, $3 \times P$. elegans, and $4 \times P$. caledonicus). For a list of individuals included and GenBank accession numbers, refer to Appendix Table 4.

\section{DNA Extraction and RAD Library Preparation}

Single end, single digest libraries were generated based on an optimization of existing protocols by Amores et al. (2011) and Etter et al. (2011). An overview of the protocol is provided here. Total genomic DNA was purified from samples using EconoSpin columns (Epoch Life Sciences, Sugar Land, Texas, USA) and a modification of the Qiagen DNeasy blood and tissue protocol (Qiagen, Valencia, California, USA). Quality was evaluated by $1 \%$ agarose gel electrophoresis and quantified using a Qubit 3.0 Fluorometer (Life Technologies, Thermo-Fisher Scientific, Waltham, Massachusetts, USA). Samples were then normalized to a concentration of $20 \mathrm{ng} \mu \mathrm{L}^{-1}$, and digested with $20 \mathrm{U}$ of restriction enzyme SbfI. P1 adapters containing unique 5-nucleotide barcodes, used to differentiate between multiplexed individuals, were ligated to each sample. Following P1 adapter ligation, samples were pooled and sheared to $\sim 400$ bases through sonication on a Covaris M220 Focused-ultrasonicator (Covaris, Woburn, Massachusetts, USA). Fragments within the desired length range ( $\sim 300-500 \mathrm{bp})$ were then retrieved by gel extraction using a QIAquick Gel Extraction kit (Qiagen). The free end of fragments was blunted to inhibit further annealing and an adenine nucleotide was added to the $3^{\prime}$ end in preparation for P2 adapter ligation. Following adapter ligation, the RADtag libraries were PCR amplified and, once again, fragments of a desired length were gel extracted (range: $\sim 250-700 \mathrm{bp}$ ). Libraries were sent to the Australian Genome Research Facility (AGRF; North Melbourne, Victoria, Australia) for sequencing on a partial lane of an Illumina HiSeq 2000 instrument (Illumina, San Diego, California, USA).

\section{RAD Data Filtering}

RAD sequencing data were filtered using program Stacks 1.35 (Catchen et al. 2013). Reads of poor quality or lacking one of the expected barcodes were filtered out using the 
process_radtags pipeline. Remaining sequences were then demultiplexed by inline barcode. As no reference genome is currently available for rosellas, reads were assembled using the denovo_map pipeline of Stacks 1.35, a minimum of 5 identical reads being required to define a locus. Subsequent filtering was carried out using the populations pipeline. Loci containing more than 1 SNP were removed to avoid linkage bias, as were SNPs containing more than 2 alleles, which presented coding problems for the analytical methods employed. Nonpolymorphic loci were likewise excluded, as they offered no additional information about tree topology, and minimum minor allele frequency was set to 0.05 . To increase the accuracy of correctly scoring homozygotes and heterozygotes, minimum read depth for a locus was increased to 20 .

Although much debate surrounds the impact of missing data on phylogenies, Huang and Knowles (2016) suggest that, for RAD data, retaining loci with missing data increases the likelihood of identifying the most accurate tree topology. This may in part be attributed to the proportional increase in data matrix size as tolerance to missing data increases. However, exclusion of loci with missing data can also result in a truncation of the distribution of mutation rates and genealogies, potentially impeding accurate phylogenetic inference. In consideration of this, we generated a dataset which permitted missing data, provided that each locus was present in at least 1 individual for each of the 6 taxonomic groups $(9,660$ loci). This requirement was necessary, as subsequent species tree analyses required that data be present for each locus at each branch. Due to limited computational resources, the full set of 9,660 loci could not be run at once. As such, 5 nonoverlapping subsets of 1,000 loci were randomly sampled from the dataset. This was done by assigning a random number to each locus using the RAND function in Excel (Microsoft Corporation, Redmond, Washington, USA). Loci were then sorted by this assigned value and the first 5,000 loci were divided into sets. In addition to these 5 datasets, a final dataset that excluded all loci with missing data was generated from the 9,660 loci. This resulted in a set of 393 loci being retained.

\section{Data Analyses}

Population genetics statistics (number of individuals genotyped, number of private alleles, number of polymorphic sites, major allele frequency, observed heterozygosity, nucleotide diversity $(\pi)$, and Wright's $F$ statistics $\left[F_{\mathrm{IS}}\right.$ and $\left.F_{\mathrm{ST}}\right]$ ) were calculated for RAD data using the populations pipeline of Stacks 1.35. Pairwise $F_{\mathrm{ST}}$ values were calculated using an AMOVA approach and applying a $P$-value correction.

STRUCTURE 2.3.4 (Pritchard et al. 2000) was used as a general clustering approach to examine whether the morphologically and geographically distinct species and subspecies were sufficiently genetically differentiated to be recovered. All 9,660 loci were included in this analysis. STRUCTURE was run for 100,000 iterations, following a burn-in of 50,000 iterations. An admixture ancestry model was employed and allele frequencies were correlated. The number of clusters $(K)$ varied from 1 to 6 , and, for each value of $K, 5$ replicate runs were conducted. Structure Harvester (Earl and Vonholdt 2012) was used to calculate $\Delta K$, thereby identifying the optimum number of clusters. Once this was selected, CLUMPP (Jakobsson and Rosenberg 2007) was used to calculate the best clustering alignment across the 5 replicates for that value of $K$ by implementing a greedy algorithm.

Species trees were estimated from RAD data in a coalescent framework using the SNP and AFLP Packages for Phylogenetic analysis (SNAPP) as implemented in BEAST 2.3.1 (Bouckaert et al. 2014), where tree tips were represented by subspecies. For this analysis, invariable sites within a locus were removed. SNPs were then recoded using the '-recode 012' function in VCFtools (https:// vcftools.github.io/man_latest.html), where 0 , 1 , or 2 indicated the number of nonreference alleles present in an individual at a given locus, and the file was manually edited to conform to a nexus format acceptable for SNAPP. When generating the SNAPP XML input files using the Bayesian Evolutionary Analysis Utility (BEAUti) in BEAST, mutation rate priors ( $U$ and $V$ ) were empirically estimated from the data. The file was also altered to reflect the fact that nonpolymorphic sites had been removed from the data. Default settings were left for other priors, but it should be noted that alterations made to these did not alter tree topology (data not included). SNAPP was run twice on all datasets (the 5 subsets of 1,000 loci and the set of 393 loci) for 3 million iterations, sampling at intervals of 500 (see Supplemental Material Appendices A-F). Output was assessed for convergence in TRACER 1.6 (Drummond and Rambaut 2007), identical runs were merged using LogCombiner 2.3.1 (Drummond and Rambaut 2007) following removal of $10 \%$ burn-in, and trees were combined using TreeAnnotator 2.3.1 (Drummond and Rambaut 2007). Tree sets were displayed using program DensiTree 2.2.3 (Bouckaert and Heled 2014), and FigTree 1.4.1 (Drummond and Rambaut 2007) was used to view and edit maximum clade credibility trees.

For comparison with the RAD topology, a species tree was generated from the ND2 data presented by Shipham et al. (2015) and using the "BEAST component of BEAST 2.3.1. All tips represented species, except where P. eximius was concerned. This species was divided into subspecies. As in Shipham et al. (2015), an HKY (Hasegawa-KishinoYano) substitution model was selected and a lognormal relaxed (uncorrected) molecular clock was used. The divergence rate was set to $2.10 \pm 0.01 \%$ (Weir and Schluter 2008, Toon et al. 2010, Shipham et al. 2015) and 
TABLE 1. Summary statistics for all taxonomic groups of Platycercus examined in this study, calculated for (A) only polymorphic nucleotide positions (variant positions), and (B) all nucleotide positions (variant and fixed positions). Statistics are calculated per group and include the mean number of individuals genotyped per locus $(n)$, the number of alleles that are unique to the group (Private), the number of polymorphic sites (Poly sites), the average frequency of the major allele (Freq), the mean observed heterozygosity $\left(H_{\text {obs }}\right)$, the mean nucleotide diversity $(\pi)$, and the mean inbreeding coefficient $\left(F_{\mathrm{IS}}\right)$.

\begin{tabular}{|c|c|c|c|c|c|c|c|}
\hline & $n$ & Private & Poly sites & Freq & $H_{\text {obs }}$ & $\pi$ & $F_{\mathrm{IS}}$ \\
\hline \multicolumn{8}{|l|}{ (A) Variant positions } \\
\hline Platycercus adscitus adscitus & 3.26 & 258 & 2,971 & 0.92 & 0.13 & 0.13 & 0.01 \\
\hline Platycercus adscitus palliceps & 3.06 & 313 & 3,453 & 0.89 & 0.14 & 0.17 & 0.06 \\
\hline Platycercus eximius eximius & 3.12 & 539 & 5,335 & 0.84 & 0.24 & 0.25 & 0.04 \\
\hline Platycercus eximius diemenensis & 3.02 & 609 & 3,241 & 0.89 & 0.14 & 0.16 & 0.03 \\
\hline Platycercus venustus venustus & 3.26 & 415 & 2,407 & 0.93 & 0.09 & 0.11 & 0.05 \\
\hline Platycercus venustus hilli & 2.77 & 372 & 1,705 & 0.95 & 0.08 & 0.09 & 0.01 \\
\hline \multicolumn{8}{|l|}{ (B) Variant and fixed positions } \\
\hline Platycercus adscitus adscitus & 3.30 & 258 & 2,971 & 1.00 & 0.00 & 0.00 & 0.00 \\
\hline Platycercus adscitus palliceps & 3.09 & 313 & 3,453 & 1.00 & 0.00 & 0.00 & 0.00 \\
\hline Platycercus eximius eximius & 3.17 & 539 & 5,335 & 1.00 & 0.00 & 0.00 & 0.00 \\
\hline Platycercus eximius diemenensis & 3.04 & 609 & 3,241 & 1.00 & 0.00 & 0.00 & 0.00 \\
\hline Platycercus venustus venustus & 3.27 & 415 & 2,407 & 1.00 & 0.00 & 0.00 & 0.00 \\
\hline Platycercus venustus hilli & 2.78 & 372 & 1,705 & 1.00 & 0.00 & 0.00 & 0.00 \\
\hline
\end{tabular}

the ploidy was altered to reflect the fact that the data was mitochondrial. Chain length was set to 10 million, and sampling was at every 1,000 iterations. For a gene tree and haplotype network generated with this data, refer to Shipham et al. (2015).

\section{RESULTS}

\section{Summary Statistics}

Following demultiplexing and initial removal of lowquality reads, the number of reads per individual ranged from $2,719,497$ to $9,168,396$. Once filtering was complete, the number of loci sequenced per individual varied from 5,298 to 9,474 (Appendix Table 3), with a mean of 7,768 loci per individual and a total of 9,660 variable loci overall. When considering only variant positions (Table 1A), the average number of individuals sampled at a given locus within a taxonomic group varied from 2.77 (P. v. hilli; $n=$ 3) to 3.26 (P. a. adscitus; $n=4$ ).

The number of polymorphic sites, observed heterozygosity, and nucleotide diversity were all lowest in P. v. hilli (Table 1), which may be attributed to the fact that only 3 individuals were sampled for this group, as opposed to 4 individuals for all other groups. However, P. v. venustus exhibited the second-lowest value for each of these measures, suggesting that lower genetic diversity may be a trait of the species. In contrast, $P$. e. eximius exhibited the highest values for these same measures, and thus appears to exhibit the highest genetic diversity. The Tasmanian $P$. e. diemenensis displayed the highest number of private alleles $(609, \sim 6 \%$ of polymorphic loci; Table 1). This may be attributed to its isolation from the other taxonomic groups, which are found on mainland Australia.

Pairwise $F_{\mathrm{ST}}$ values were calculated across the dataset of 9,660 variable loci. Values were lowest when comparing subspecies within a given species $\left(F_{\mathrm{ST}}<0.09\right.$; Table 2$)$, and highest when comparing the most southerly group, $P . e$. diemenensis, with the most northerly groups, $P$. v. hilli $\left(F_{\mathrm{ST}}\right.$ $=0.39), P$. v. venustus $\left(F_{\mathrm{ST}}=0.34\right)$, and $P$. a. adscitus $\left(F_{\mathrm{ST}}=\right.$ 0.32; Table 2). Despite being separated by the Bass Strait, $P$. eximius subspecies had only a marginally higher pairwise $F_{\mathrm{ST}}$ value than $P$. adscitus subspecies and had a lower $F_{\mathrm{ST}}$ value than $P$. venustus subspecies. $P$. adscitus hybridize in Queensland, while P. venustus may hybridize (Schodde 1997) or may exhibit a geographical break (Higgins 1999) in the region of the Victoria River, Northern Territory. In general, pairwise $F_{\mathrm{ST}}$ values were greater between $P$. $a$.

TABLE 2. Pairwise comparisons of genetic differentiation $\left(F_{\mathrm{ST}}\right)$ between taxonomic groups of Platycercus examined in this study.

\begin{tabular}{lccccc}
\hline & $\begin{array}{c}\text { P. adscitus } \\
\text { adscitus }\end{array}$ & $\begin{array}{c}\text { P. adscitus } \\
\text { palliceps }\end{array}$ & $\begin{array}{c}\text { P. eximius } \\
\text { eximius }\end{array}$ & $\begin{array}{c}\text { P. eximius } \\
\text { diemenensis }\end{array}$ & $\begin{array}{c}\text { P. venustus } \\
\text { venustus }\end{array}$ \\
\hline P. adscitus adscitus & & 0.035 & 0.180 & 0.317 & 0.153 \\
P. adscitus palliceps & & 0.138 & 0.264 & 0.130 \\
P. eximius eximius & & & 0.035 & 0.212 & 0.178 \\
P. eximius diemenensis & & & & 0.344 \\
P. venustus venustus & & & & 0.240 \\
\hline
\end{tabular}




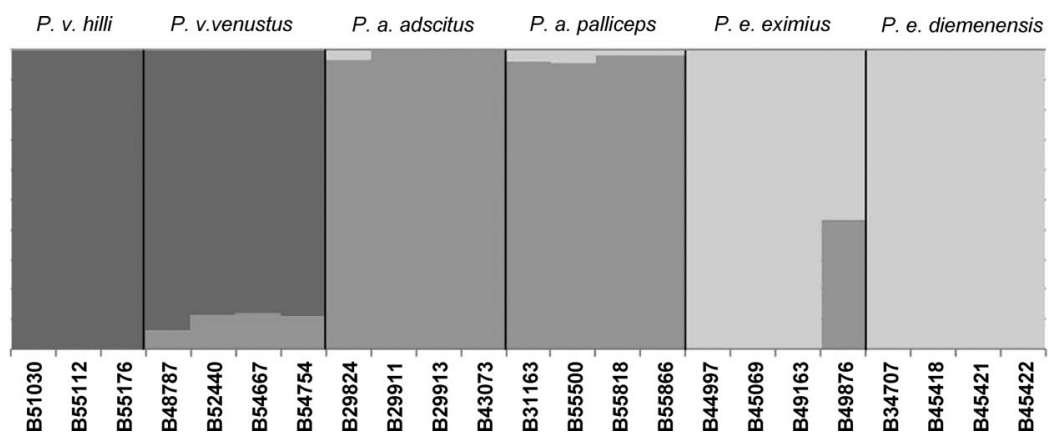

FIGURE 2. Results of a STRUCTURE (Pritchard et al. 2000) clustering analysis of Platycercus venustus, $P$. adscitus, and $P$. eximius, where the number of clusters $(K)=3$ and including data from 9,660 loci. Black lines split species and subspecies, which were identified based on phenotypic characteristics and geographic location. Individuals used in the analysis are represented by their Australian National Wildlife Collection accession numbers (see Appendix Table 3).

adscitus and other taxonomic groups than when comparing $P$. a. palliceps with those same groups.

\section{Clustering}

The results of our STRUCTURE analysis returned an optimum value of $K=3$. Clusters largely corresponded to the 3 species (Figure 2), and increasing $K$ did not significantly improve our ability to distinguish between subspecies. This is to be expected as, when presented with a hierarchically structured system, STRUCTURE first identifies the most significantly differentiated groups (Evanno et al. 2005). Overall, the sampling design was mostly successful at avoiding hybrid individuals. There was 1 major exception to this, as $1 P$. e. eximius individual (B49876) appeared to be of admixed ancestry (Figure 2), despite being found considerably south of the putative hybrid zone and being purely $P$. eximius in appearance. STRUCTURE also revealed a consistently low level $(<12 \%)$ of apparent admixture from $P$. adscitus in all $4 P$. v. venustus individuals, which did not extend to $P$. v. hilli (Figure 2). This may be the result of isolation by distance, which STRUCTURE is reportedly sensitive to (Pritchard et al. 2000), and which can be seen from the $F_{\mathrm{ST}}$ values presented herein (Table 2).

\section{Phylogenetic Analysis}

Tree topology was consistent across all RAD datasets. As such, only the maximum clade credibility tree and tree set from the first subset of 1,000 loci have been displayed here (generated using the XML file in Supplemental Material Appendix A). The results of the SNAPP analyses were consistent with a sister relationship between $P$. adscitus and $P$. venustus and with $P$. eximius being their sister taxon and more distantly related (Figures 3A, 3B). This was in spite of the presence of an apparent $P$. eximius $-P$. adscitus admixed individual (Figure 2), which would have acted to decrease the apparent differentiation between these 2 taxa (Leache et al. 2014). Following identification of this individual, additional SNAPP analyses were run excluding it and also excluding $P$. $v$. venustus (due to the low level of admixture identified by STRUCTURE). When the admixed individual was removed from the analysis, tree topology did not differ (Appendix Figure 4A). Nor did it change with the removal of $P$. v. venustus (Appendix Figure 4B). Species trees were well resolved, and had posterior probabilities of 1 for all nodes (Figure 3A). Tree topology did not differ between datasets or with tolerance to missing data, and plotting tree sets revealed topological concordance among individual trees (Figure 3B). Trace
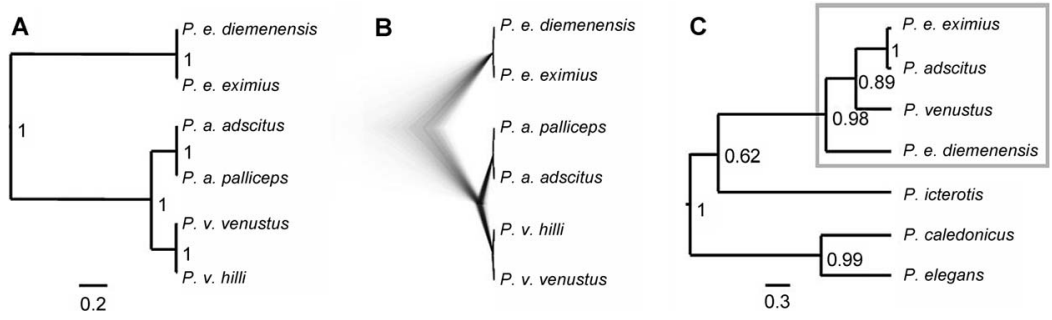

FIGURE 3. Species trees showing the evolutionary relationships among Platycercus venustus, $P$. adscitus, and $P$. eximius, generated using program BEAST (Bouckaert et al. 2014). (A) Maximum clade credibility tree, with values at nodes indicating posterior probabilities. (B) Tree set used to generate the maximum clade credibility tree and showing no topological discordance between individual trees. (C) ND2 species tree, with values at nodes indicating posterior probabilities (light gray box denotes relationships of interest). Scale bars show branch lengths as measured in millions of years (ND2) or expected mutations per site (RAD loci). 
files showed that convergence was reached for key parameters in all datasets (effective sample size [ESS] > 100).

The tree topology generated using RAD SNP data differed from that presented in the ND2 species tree (Figure 3C; Shipham et al. 2015). P. eximius subspecies aligned together according to RAD data but not ND2 data. Instead, with ND2, nominotypical $P$. e. eximius aligned as sister to $P$. adscitus, while the Tasmanian $P$. e. diemenensis was sister to all other taxonomic groups.

\section{DISCUSSION}

In their recent phylogenetic analysis of the rosella genus Platycercus, using 1 mitochondrial and 9 nuclear loci, Shipham et al. (2015) reported a mitonuclear disparity in relationships among $P$. adscitus, $P$. venustus, and $P$. eximius. They inferred this to be the result of either incomplete lineage sorting (ILS) or mitochondrial introgression, favoring the latter. In the present study, thousands of loci have been used to clearly and consistently support a sister relationship between $P$. adscitus and $P$. venustus, and place $P$. eximius as their sister. This same relationship was recovered by Shipham et al. (2015). However, this finding needs to be reconciled with findings based on mitochondrial markers, which suggest that $P$. adscitus is more closely related to nominotypical, mainland $P$. e. eximius (Ovenden et al. 1987, Shipham et al. 2015), whereas geographically isolated Tasmanian $P$. e diemenensis is recovered as sister to other rosellas in the subgenus Violania, so rendering P. eximius paraphyletic (Figure 3; Shipham et al. 2015). We argue that these results can be reconciled if the mtDNA paraphyly is due to mtDNA capture following introgression of $P$. adscitus mtDNA into mainland $P$. e. eximius, while geographically isolated $P$. $e$. diemenensis has retained the original $P$. eximius mtDNA. Our results support a new example of mitonuclear discordance between widespread species in eastern Australia, and we now consider potential explanations more closely.

ILS was potentially problematic in the sequence dataset presented by Shipham et al. (2015), as the nuclear loci had poor resolving power (on average, 24 polymorphic sites per locus). Support for key nodes was not consistently high, even when all loci were combined (posterior probabilities as low as 0.61 ), and topological inconsistencies arose when only nuclear loci were included in a species tree (Shipham et al. 2015). ILS is a common problem when examining nuclear loci due to their typically lower rate of mutation, and is particularly evident for species that have diverged relatively recently. The taxa examined here have been estimated to have diverged since the Pleistocene and potentially as recently as 0.1617 mya (Shipham et al. 2015). RAD sequencing has been reported to offer greater power for phylogenetic inference (Herrera and Shank 2016), so the consistency in topology across 6 RAD datasets, containing a combined total of $\geq 5,000$ unique loci sampled from across the rosella genome, is unlikely to be the result of ILS.

Assuming that the conflicting patterns identified using RAD sequencing and mitochondrial data are both accurate reflections of elements of the birds' histories, then the data clearly favor an explanation that accommodates extensive gene flow and introgression, most likely of mtDNA. Shipham et al. (2015) found very little genetic differentiation between the mtDNA of $P$. adscitus and mainland $P$. $e$. eximius. That is, a central haplotype of $P$. adscitus was found to be shared throughout the range of both taxa, but did not occur in any other taxon. No other haplotype was shared among taxonomic groups. The conflicting placement of the isolated Tasmanian subspecies $P$. $e$. diemenensis within the taxonomic framework offers additional support for mitochondrial introgression. Our fundamental expectation would be for $P$. e. diemenensis and $P$. e. eximius to align together, regardless of marker type. However, because the mtDNA of $P$. e. diemenensisis placed this taxon as sister to the rest of the complex under consideration here (P. adscitus, $P$. venustus, and $P$. e . eximius), we favor the alternative hypothesis of mitochondrial introgression or capture for explaining the mitonuclear discordance first proposed by Shipham et al. (2015). That is, mitochondrial introgression has occurred from $P$. adscitus into mainland populations of $P$. eximius, but not those isolated on Tasmania, which still retain 'true' $P$. eximius mtDNA (Shipham et al. 2015). The pattern detected using mtDNA was consistent across multiple marker types (RFLPs: Ovenden et al. 1987; ND2 sequence data: Shipham et al. 2015), lending confidence to these findings. Additionally, strong evidence of mitochondrial introgression or capture has been found across a range of taxonomic groups (see Toews and Brelsford 2012, Good et al. 2015). Pomatorhinus spp. (Scimitar babblers; Dong et al. 2014) and Emberiza spp. (yellowhammers and pine buntings; Irwin et al. 2009) represent 2 cases in which strong evidence of extensive mitochondrial introgression or capture has been identified in non-Australian avian species, and McLean et al. (2012) acknowledge that mtDNA paraphyly is not an uncommon occurrence in Australian avian taxa, stating introgression as an oft-used explanation (e.g., Zosterops spp. [white eyes]; Degnan and Moritz 1992). Our findings also strongly parallel another instance in Australian birds of mitochondrial introgression involving nonsister taxa, that of Cracticus spp. (butcherbirds; Kearns et al. 2014). Given that P. adscitus and $P$. eximius share an assumed hybrid zone where their ranges overlap (Cannon 1984), ongoing introgression is feasible.

To some extent, the present hypothesis contradicts the expectations of Haldane's rule, which states that when 2 
divergent lineages hybridize, the heterogametic sex often exhibits reduced fertility (Haldane 1922, Gowen et al. 2014). It therefore follows that mitochondrial introgression is less likely to occur when the female is the heterogametic sex, as is the case in birds (Jacobsen and Omland 2011, Gowen et al. 2014). Although many taxa appear to conform to this general rule, we have presented several instances above in which avian taxa display strong evidence of mitochondrial introgression (also see Toews and Brelsford 2012). While the mechanisms driving Haldane's rule are under continued examination, the most common explanation is that genetic incompatibilities which arise during periods of divergence between lineages are expressed in heterogametic hybrid offspring (Schilthuizen et al. 2011). The likely replacement of mainland $P$. eximius mtDNA with $P$. adscitus mtDNA may therefore indicate that selection against heterogametic hybrids (if present at all) was asymmetrical between these taxa (i.e. against hybrid offspring with $P$. eximius mothers), and/or that selection may have favored $P$. adscitus mtDNA on a $P$. eximius nuclear background. Alternatively, potential demographic differences such as sex-biased dispersal and/or an increase in the rate of genetic drift as a result of asymmetrical population sizes in $P$. adscitus and $P$. eximius may have aided in the widespread introgression and fixation of $P$. adscitus mtDNA at some point in the past (Toews and Brelsford 2012).

Thus far, we have discussed the 2 most likely explanations for the mitonuclear discordance observed in the current dataset and that presented by Shipham et al. (2015). There are a number of other potential explanations for such discordance, although none appear more adequate than mitochondrial introgression and capture. For instance, mitonuclear discordance may result from unusually low mtDNA substitution rates. Ovenden et al. (1987) briefly suggested this as a possibility in rosellas, but discarded it in favor of a rate of mtDNA mutation more similar to mammals. The potential argument for a lower substitution rate relied on rosellas having a large long-term effective population size, which was inconsistent with the gene tree. It was argued that persistence of ancestral polymorphisms would have resulted in an observed pattern of phylogenies crossing species or population boundaries, a pattern that was not identified in their analyses. Our data corroborate this finding, as ND2 divergence within the genus largely followed expected divergence patterns. For instance, P. icterotis in Western Australia was found to be distinctly differentiated from other rosellas in the subgenus Violania (Shipham et al. 2015). This pattern can be found in a number of other avian taxa (e.g., Murphy et al. 2011, Dolman and Joseph 2012).

Mitonuclear discordance might also be expected if there were strong purifying selection on the mtDNA of $P$. adscitus and P. eximius. However, this seems unlikely due to their latitudinal distribution, as variation in climatic conditions has increasingly been associated with the adaptive evolution of mtDNA (Ballard and Whitlock 2004, Balloux et al. 2009). Recently, Pavlova et al. (2013) and Morales et al. (2015) attributed the structuring of mitochondrial variation in the Eastern Yellow Robin (Eopsaltria australis) largely to environmental temperatures and positive selection on mtDNA. This species displays a similar geographical distribution to $P$. adscitus and $P$. eximius. In the event that selective pressures have had an influence, we suggest that positive, rather than purifying, selection would be a more likely explanation. Positive selection on ND2 has been identified in other avian taxa (Stager et al. 2014), and the complex to which ND2 belongs (NADH dehydrogenase) has often been associated with adaptive evolution (e.g., Meiklejohn et al. 2007, da Fonseca et al. 2008). Additionally, a number of studies have now identified patterns of introgression consistent with positive selection (Anderson et al. 2009, Norris et al. 2015). Further study is required to discern whether or not selection has played a role in generating the pattern of mitonuclear discordance identified between the rosella species under consideration here. In particular, focus on the putative $P$. eximius $-P$. adscitus hybrid zone may reveal sex-biased mating and/or movement across the zone or asymmetries in offspring survival that may account for the discrepancy (Toews and Brelsford, 2012).

In clarifying the sister relationship between $P$. adscitus and $P$. venustus, and in identifying evidence of mitochondrial introgression from $P$. adscitus into mainland $P$. eximius, this study joins a growing body of literature which has found evidence of naturally occurring hybridization between nonsister species (see McCarthy 2006, Mallet et al. 2007, Gholamhosseini et al. 2013, Kearns et al. 2014). The complex history of these hybridizing taxa provides an opportunity for future research into the mechanisms maintaining species boundaries in the face of gene flow, and may provide important insights into the porous nature of genomic and species boundaries.

\section{ACKNOWLEDGMENTS}

We are grateful to Robert Palmer, Alex Drew, and Richard Schodde of the Australian National Wildlife Collection for providing tissue samples and helpful discussion for this study, as well as Kathryn Real and members of the Griffith University molecular ecology laboratory for assistance with laboratory-related matters and feedback on various aspects of the research. We thank all scientific permit-granting agencies who have allowed collection of specimens used in this study. We thank Dr. Remco Bouckaert for advice relating to the BEAST2 package SNAPP, and Peter Rothlisberg for assistance with the initial structuring of this paper as part of a scientific paper writing workshop held by the Australian Rivers 
Institute. We gratefully acknowledge the support of the Griffith University eResearch Services Team and the use of the High Performance Computing Cluster 'Gowonda' to complete this research, and acknowledge the work of the Australian Genome Research Facility who performed the sequencing of our RAD tag libraries.

Funding statement: This research was funded by Griffith University, CSIRO National Research Collections Australia, and a grant from the Frank M. Chapman Memorial Fund, American Museum of Natural History. None of the funders had input into the content of the manuscript, nor required their approval of the manuscript prior to submission or publication.

Ethics statement: All samples were provided by the Australian National Wildlife Collection and had been collected by that group before this work commenced with all necessary ethics protocols and scientific collecting permits. Author contributions: All authors were involved in conceiving the idea for this research, and in writing and/or substantially editing the paper. A.S. performed the experiments. Methods were predominantly developed or designed by D.J.S., while A.S. and D.J.S. analyzed the data. L.J. contributed considerable materials and funding.

\section{LITERATURE CITED}

Amores, A., J. Catchen, A. Ferrara, Q. Fontenot, and J. H. Postlethwait (2011). Genome evolution and meiotic maps by massively parallel DNA sequencing: Spotted gar, an outgroup for the teleost genome duplication. Genetics 188:799-808.

Anderson, T. M., B. M. vonHoldt, S. I. Candille, M. Musiani, C. Greco, D. R. Stahler, D. W. Smith, B. Padhukasahasram, E. Randi, J. A. Leonard, C. D. Bustamante, et al. (2009). Molecular and evolutionary history of melanism in North American gray wolves. Science 323:1339-1343.

Baird, N. A., P. D. Etter, T. S. Atwood, M. C. Currey, A. L. Shiver, Z. A. Lewis, E. U. Selker, W. A. Cresko, and E. A. Johnson (2008). Rapid SNP discovery and genetic mapping using sequenced RAD markers. PLOS One 3:e3376. doi:10.1371/journal.pone. 0003376

Ballard, J. W. O., and M. C. Whitlock (2004). The incomplete natural history of mitochondria. Molecular Ecology 13:729744.

Balloux, F., L. J. L. Handley, T. Jombart, H. Liu, and A. Manica (2009). Climate shaped the worldwide distribution of human mitochondrial DNA sequence variation. Proceedings of the Royal Society of London, Series B 276:3447-3455.

Bouckaert, R., and J. Heled (2014). DensiTree 2: Seeing trees through the forest. bioRxiv:012401. http://dx.doi.org/10. $1101 / 012401$

Bouckaert, R., J. Heled, D. Kühnert, T. Vaughan, C.-H. Wu, D. Xie, M. A. Suchard, A. Rambaut, and A. J. Drummond (2014). BEAST 2: A software platform for Bayesian evolutionary analysis. PLOS Computational Biology 10:e1003537. doi: 1003510.1001371/journal.pcbi.1003537

Cain, A. J. (1955). A revision of Trichoglossus haematodus and of the Australian platycercine parrots. Ibis 97:432-479.

Cannon, E. C. (1984). Rosellas, Platycercus spp., and their hybrids in the eastern Queensland-New South Wales border region. Australian Zoologist 21:175-183.
Catchen, J., P. A. Hohenlohe, S. Bassham, A. Amores, and W. A. Cresko (2013). Stacks: An analysis tool set for population genomics. Molecular Ecology 22:3124-3140.

Corl, A., and H. Ellegren (2013). Sampling strategies for species trees: The effects on phylogenetic inference of the number of genes, number of individuals, and whether loci are mitochondrial, sex-linked, or autosomal. Molecular Phylogenetics and Evolution 67:358-366.

DaCosta, J. M., and M. D. Sorenson (2016). ddRAD-seq phylogenetics based on nucleotide, indel, and presenceabsence polymorphisms: Analyses of two avian genera with contrasting histories. Molecular Phylogenetics and Evolution 94:122-135.

da Fonseca, R. R., W. E. Johnson, S. J. O'Brien, M. J. Ramos, and A. Antunes (2008). The adaptive evolution of the mammalian mitochondrial genome. BMC Genomics 9:119. doi:10.1186/ 1471-2164-9-119

Degnan, J. H., and N. A. Rosenberg (2009). Gene tree discordance, phylogenetic inference and the multispecies coalescent. Trends in Ecology \& Evolution 24:332-340.

Degnan, S. M., and C. Moritz (1992). Phylogeography of mitochondrial DNA in two species of white-eyes in Australia. The Auk 109:800-811.

Dolman, G., and L. Joseph (2012). A species assemblage approach to comparative phylogeography of birds in southern Australia. Ecology and Evolution 2:354-369.

Dong, F., F.-S. Zou, F.-M. Lei, W. Liang, S.-H. Li, and X.-J. Yang (2014). Testing hypotheses of mitochondrial gene-tree paraphyly: Unravelling mitochondrial capture of the Streakbreasted Scimitar Babbler (Pomatorhinus ruficollis) by the Taiwan Scimitar Babbler (Pomatorhinus musicus). Molecular Ecology 23:5855-5867.

Drummond, A. J., and A. Rambaut (2007). BEAST: Bayesian evolutionary analysis by sampling trees. BMC Evolutionary Biology 7:214. doi:10.1186/1471-2148-7-214

Earl, D. A., and B. M. Vonholdt (2012). STRUCTURE HARVESTER: A website and program for visualizing STRUCTURE output and implementing the Evanno method. Conservation Genetics Resources 4:359-361.

Emerson, K. J., C. R. Merz, J. M. Catchen, P. A. Hohenlohe, W. A. Cresko, W. E. Bradshaw, and C. M. Holzapfel (2010). Resolving postglacial phylogeography using high-throughput sequencing. Proceedings of the National Academy of Sciences USA 107:16196-16200.

Etter, P. D., S. Bassham, P. A. Hohenlohe, E. A. Johnson, and W. A. Cresko (2011). SNP discovery and genotyping for evolutionary genetics using RAD sequencing. Methods in Molecular Biology 772:157-178.

Evanno, G., S. Regnaut, and J. Goudet (2005). Detecting the number of clusters of individuals using the software STRUCTURE: A simulation study. Molecular Ecology 14: 2611-2620.

Forshaw, J. M. (2002). Australian Parrots, third edition. Alexander Editions, Robina, QLD, Australia.

Gholamhosseini, A., M. Vardakis, M. Aliabadian, V. Nijman, and R. Vonk (2013). Hybridization between sister taxa versus nonsister taxa: A case study in birds. Bird Study 60:195-201.

Good, J. M., D. Vanderpool, S. Keeble, and K. Bi (2015). Negligible nuclear introgression despite complete mitochondrial capture between two species of chipmunks. Evolution 69:19611972. 
Gowen, F. C., J. M. Maley, C. Cicero, A. T. Peterson, B. C. Faircloth, T. C. Warr, and J. E. McCormack (2014). Speciation in Western Scrub-Jays, Haldane's rule, and genetic clines in secondary contact. BMC Evolutionary Biology 14:135. http://www. biomedcentral.com/1471-2148/14/135

Haldane, J. B. S. (1922). Sex ratio and unisexual sterility in hybrid animals. Journal of Genetics 12:101-109.

Herrera, S., and T. M. Shank (2016). RAD sequencing enables unprecedented phylogenetic resolution and objective species delimitation in recalcitrant divergent taxa. Molecular Phylogenetics and Evolution 100:70-79.

Higgins, P. J. (Editor) (1999). Handbook of Australian, New Zealand and Antarctic Birds, Volume 4: Parrots to Dollarbirds. Oxford University Press, Melbourne, VIC, Australia.

Huang, H., and L. L. Knowles (2016). Unforeseen consequences of excluding missing data from next-generation sequences: Simulation study of RAD sequences. Systematic Biology 65: 357-365.

Irwin, D. E., A. S. Rubtsov, and E. N. Panov (2009). Mitochondrial introgression and replacement between Yellowhammers (Emberiza citrinella) and Pine Buntings (Emberiza leucocephalos) (Aves: Passeriformes). Biological Journal of the Linnean Society 98:422-438.

Jacobsen, F., and K. E. Omland (2011). Species tree inference in a recent radiation of orioles (genus Icterus): Multiple markers and methods reveal cytonuclear discordance in the northern oriole group. Molecular Phylogenetics and Evolution 61:460-469.

Jakobsson, M., and N. A. Rosenberg (2007). CLUMPP: A cluster matching and permutation program for dealing with label switching and multimodality in analysis of population structure. Bioinformatics 23:1801-1806.

Kearns, A. M., L. Joseph, A. Toon, and L. G. Cook (2014). Australia's arid-adapted butcherbirds experienced range expansions during Pleistocene glacial maxima. Nature Communications 5:3994. doi:10.1038/ncomms4994

Leache, A. D., R. B. Harris, B. Rannala, and Z. H. Yang (2014). The influence of gene flow on species tree estimation: A simulation study. Systematic Biology 63:17-30.

Mallet, J., M. Beltran, W. Neukirchen, and M. Linares (2007). Natural hybridization in heliconiine butterflies: The species boundary as a continuum. BMC Evolutionary Biology 7:1-16.

McCarthy, E. M. (2006). Handbook of Avian Hybrids of the World. Oxford University Press, New York, NY, USA.

McCormack, J. E., S. M. Hird, A. J. Zellmer, B. C. Carstens, and R. T. Brumfield (2013). Applications of next-generation sequencing to phylogeography and phylogenetics. Molecular Phylogenetics and Evolution 66:526-538.

McLean, A. J., A. Toon, D. J. Schmidt, L. Joseph, and J. M. Hughes (2012). Speciation in Chestnut-shouldered Fairy-Wrens (Malurus spp.) and rapid phenotypic divergence in Variegated Fairy-Wrens (Malurus lamberti): A multilocus approach. Molecular Phylogenetics and Evolution 63:668-678.

Meiklejohn, C. D., K. L. Montooth, and D. M. Rand (2007). Positive and negative selection on the mitochondrial genome. Trends in Genetics 23:259-263.

Morales, H. E., A. Pavlova, L. Joseph, and P. Sunnucks (2015). Positive and purifying selection in mitochondrial genomes of a bird with mitonuclear discordance. Molecular Ecology 24: 2820-2837.
Murphy, S. A., L. Joseph, A. H. Burbidge, and J. Austin (2011). A cryptic and critically endangered species revealed by mitochondrial DNA analyses: The Western Ground Parrot. Conservation Genetics 12:595-600.

Norris, L. C., B. J. Main, Y. Lee, T. C. Collier, A. Fofana, A. J. Cornel, and G. C. Lanzaro (2015). Adaptive introgression in an African malaria mosquito coincident with the increased usage of insecticide-treated bed nets. Proceedings of the National Academy of Sciences USA 112:815-820.

Ovenden, J. R., A. G. Mackinlay, and R. H. Crozier (1987). Systematics and mitochondrial genome evolution of Australian rosellas (Aves, Platycercidae). Molecular Biology and Evolution 4:526-543.

Pavlova, A., J. N. Amos, L. Joseph, K. Loynes, J. J. Austin, J. S. Keogh, G. N. Stone, J. A. Nicholls, and P. Sunnucks (2013). Perched at the mito-nuclear crossroads: Divergent mitochondrial lineages correlate with environment in the face of ongoing nuclear gene flow in an Australian bird. Evolution 67:3412-3428.

Pritchard, J. K., M. Stephens, and P. Donnelly (2000). Inference of population structure using multilocus genotype data. Genetics 155:945-959.

Schilthuizen, M., M. C. W. G. Giesbers, and L. W. Beukeboom (2011). Haldane's rule in the $21^{\text {st }}$ century. Heredity 107:95102.

Schodde, R. (1997). Psittacidae. In Volume 37.2: Aves (Columbidae to Coraciidae) of the Zoological Catalogue of Australia (W. M. K. Houston and A. Wells, Editors). CSIRO Publishing, Melbourne, Australia. pp. 109-218.

Shipham, A., D. J. Schmidt, L. Joseph, and J. M. Hughes (2015). Phylogenetic analysis of the Australian rosella parrots (Platycercus) reveals discordance among molecules and plumage. Molecular Phylogenetics and Evolution 91:150159.

Stager, M., D. J. Cerasale, R. Dor, D. W. Winkler, and Z. A. Cheviron (2014). Signatures of natural selection in the mitochondrial genomes of Tachycineta swallows and their implications for latitudinal patterns of the 'pace of life'. Gene 546:104-111.

Steiner, C. C., A. Mitelberg, R. Tursi, and O. A. Ryder (2012). Molecular phylogeny of extant equids and effects of ancestral polymorphism in resolving species-level phylogenies. Molecular Phylogenetics and Evolution 65:573-581.

Toews, D. P. L., and A. Brelsford (2012). The biogeography of mitochondrial and nuclear discordance in animals. Molecular Ecology 21:3907-3930.

Toews, D. P. L., L. Campagna, S. A. Taylor, C. N. Balakrishnan, D. T. Baldassarre, P. E. Deane-Coe, M. G. Harvey, D. M. Hooper, D. E. Irwin, C. D. Judy, N. A. Mason, et al. (2016). Genomic approaches to understanding population divergence and speciation in birds. The Auk: Ornithological Advances 133:1330.

Toon, A., J. M. Hughes, and L. Joseph (2010). Multilocus analysis of honeyeaters (Aves: Meliphagidae) highlights spatio-temporal heterogeneity in the influence of biogeographic barriers in the Australian monsoonal zone. Molecular Ecology 19:2980-2994.

Weir, J. T., and D. Schluter (2008). Calibrating the avian molecular clock. Molecular Ecology 17:2321-2328. 
APPENDIX TABLE 3. Coordinates of individual sampling locations, number of reads following initial demultiplexing and removal of low-quality reads (\# raw reads), and number of loci present after filtering (\# filtered loci) for taxonomic groups of Platycercus examined in this study. Individuals are identified by their Australian National Wildlife Collection accession number (ANWC ID). An asterisk (*) indicates individuals that were also included by Shipham et al. (2015).

\begin{tabular}{|c|c|c|c|c|c|}
\hline ANWC ID & Species & Latitude & Longitude & \# raw reads & \# filtered loci \\
\hline B29824 & P. adscitus adscitus & -12.5583 & 141.9375 & $7,123,997$ & 8,725 \\
\hline B29911 & P. adscitus adscitus & -13.8464 & 143.1453 & $8,951,505$ & 9,435 \\
\hline B29913 & P. adscitus adscitus & -13.8464 & 143.1453 & $5,130,473$ & 8,048 \\
\hline B43073 & P. adscitus adscitus & -13.8417 & 143.4611 & $2,719,497$ & 5,298 \\
\hline B31163* & P. adscitus palliceps & -20.9217 & 148.9200 & $8,374,271$ & 9,349 \\
\hline B55500* & P. adscitus palliceps & -23.6229 & 146.2706 & $2,858,061$ & 6,185 \\
\hline B55818 & P. adscitus palliceps & -19.6576 & 146.8352 & $3,110,485$ & 6,861 \\
\hline B55866 & P. adscitus palliceps & -21.3962 & 146.8648 & $3,547,625$ & 7,208 \\
\hline B44997* & P. eximius eximius & -38.3117 & 143.0381 & $3,025,641$ & 6,630 \\
\hline B45069 & P. eximius eximius & -37.2650 & 142.2511 & $4,261,126$ & 7,851 \\
\hline B49163 & P. eximius eximius & -36.0353 & 147.3125 & $3,007,390$ & 6,534 \\
\hline B49876 & P. eximius eximius & -34.5153 & 146.7714 & $8,658,845$ & 9,079 \\
\hline B34707* & P. eximius diemenensis & -42.8833 & 147.3167 & $4,489,230$ & 5,685 \\
\hline B45418* & P. eximius diemenensis & -42.0339 & 147.3083 & $4,638,858$ & 8,768 \\
\hline B45421 & P. eximius diemenensis & -42.0339 & 147.3083 & $3,392,514$ & 7,805 \\
\hline B45422 & P. eximius diemenensis & -42.0339 & 147.3083 & $3,461,640$ & 6,947 \\
\hline B48787 & $P$. venustus venustus & -11.7794 & 130.9008 & $2,952,268$ & 6,560 \\
\hline B52440 & $P$. venustus venustus & -14.0620 & 133.8250 & $3,927,258$ & 7,941 \\
\hline B54667 & $P$. venustus venustus & -14.7440 & 134.3800 & $8,321,713$ & 9,328 \\
\hline B54754 & $P$. venustus venustus & -14.0620 & 133.8250 & $3,912,405$ & 7,626 \\
\hline B51030 & P. venustus hilli & -15.5333 & 128.6333 & $9,168,396$ & 9,465 \\
\hline B55112 & P. venustus hilli & -16.3559 & 128.1691 & $8,421,681$ & 9,474 \\
\hline B55176 & P. venustus hilli & -16.6535 & 128.2458 & $3,846,332$ & 7,862 \\
\hline
\end{tabular}

APPENDIX TABLE 4. List of ND2 samples and associated GenBank accession numbers (GenBank) taken from Shipham et al. (2015) and used in the construction of an mtDNA species tree for taxonomic groups of Platycercus. Individual samples are identified by their Australian National Wildlife Collection accesssion number (ANWC ID).

\begin{tabular}{lll}
\hline ANWC ID & \multicolumn{1}{c}{ Species } & GenBank \\
\hline B28875 & P. icterotis & KR780594 \\
B31931 & P. icterotis & KR780593 \\
B48604 & P. venustus & KR780611 \\
B54667 & P. venustus & KR780609 \\
B55111 & P. venustus & KR780610 \\
B29823 & P. adscitus & KR780612 \\
B49085 & P. adscitus & KR780614 \\
B31163 & P. adscitus & KR780613 \\
B55500 & P. adscitus & KR780615 \\
B33830 & P. eximius eximius & KR780595 \\
B34405 & P. eximius eximius & KR780596 \\
B44997 & P. eximius eximius & KR780598 \\
B49876 & P. eximius eximius & KR780601 \\
B34707 & P. eximius diemenensis & KR780597 \\
B45418 & P. eximius diemenensis & KR780599 \\
B49786 & P. eximius diemenensis & KR780600 \\
B44800 & P. elegans & KR780608 \\
B34118 & P. elegans & KR780607 \\
B49456 & P. elegans & KR780606 \\
B34705 & P. caledonicus & KR780604 \\
B45357 & P. caledonicus & KR780605 \\
B45439 & P. caledonicus & KR780602 \\
B45827 & P. caledonicus & KR780603 \\
\hline
\end{tabular}


A

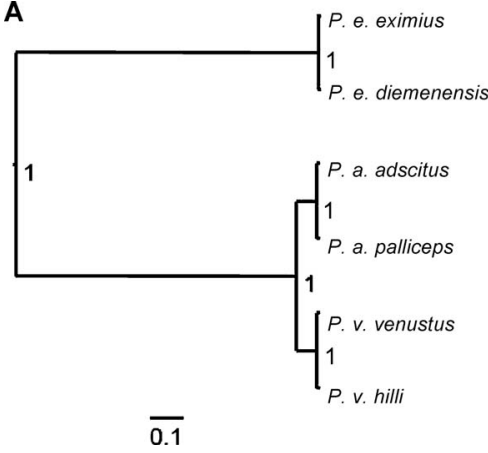

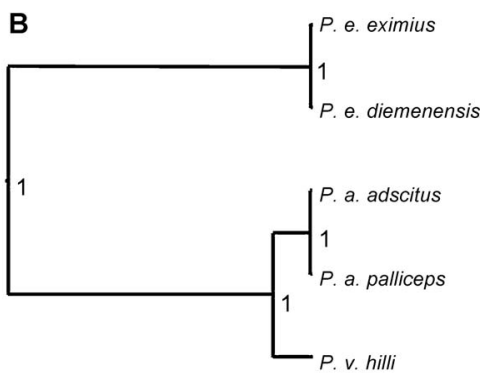

0.2

APPENDIX FIGURE 4. Maximum clade credibility trees showing evolutionary relationships among Platycercus venustus, $P$. adscitus, and $P$. eximius, generated using the SNAPP package implemented in program BEAST (Bouckaert et al. 2014). Species trees were constructed using datasets excluding loci with missing data, and either (A) excluding sample B49876 ( $n=22$, loci = 399), or (B) excluding sample B49876 and P. v. venustus individuals $(n=18$, loci $=717)$. Only loci containing single, biallelic SNPs with minimum minor allele frequencies $\geq 0.05$ and stack depths $\geq 20$ were included. Modification of SNAPP settings included empirical estimation of mutation rate priors and notification of removal of nonpolymorphic sites. Chain length was set to 5 million (sampled every 500). The analysis excluding only B49876 required 1 run to reach convergence, while that additionally excluding $P$. $v$. venustus required the combination of 2. Values at nodes indicate posterior probabilities. Scale bar shows branch lengths as measured in expected mutations per site. 